\title{
A systematic review of undisplaced femoral neck fracture treatments for patients over 65 years of age, with a focus on union rates and avascular necrosis
}

\author{
Dan-Feng $\mathrm{Xu}^{1}$, Fang-Gang Bi ${ }^{2}$, Chi-Yuan Ma', Zheng-Fa Wen ${ }^{3}$ and Xun-Zi Cai ${ }^{1 *}$
}

\begin{abstract}
Background: It remains unclear whether conservative treatment should be used to treat the common undisplaced femoral neck fractures that develop in the elderly. Herein, we systematically review the rates of union and avascular necrosis after conservative and surgical treatment of undisplaced femoral neck fractures.

Methods: We searched the EMBASE, PubMed, OVID, Cochrane Library, Web of Science, and Scopus databases for randomized controlled trials or observational studies that assessed the outcomes of conservative or surgical treatments of undisplaced femoral neck fractures. No language or publication year limitation was imposed. Statistical analyses were performed with the aid of the chi-squared test. We evaluated the quality of each publication and the risk of bias.
\end{abstract}

Results: Twenty-nine studies involving 5071 patients were ultimately included; 1120 patients were treated conservatively and 3951 surgically. The union rates were 68.8\% (642/933) and 92.6\% (635/686) in the former and latter groups, respectively $(p<0.001)$. The avascular necrosis rate in the conservatively treated group was $10.3 \%$ (39/380), while it was $7.7 \%(159 / 2074)$ in the surgically treated group $(p=0.09)$.

Conclusions: Surgery to treat undisplaced femoral neck fractures was associated with a higher union rate and a tendency toward less avascular necrosis than conservative treatment.

Keywords: Undisplaced femoral neck fracture, Surgical treatment, Conservative treatment, Secondary displacement, Non-union, Avascular necrosis

\section{Background}

A femoral neck fracture (FNF) is one of the most common and devastating injuries encountered by orthopedic surgeons. Over 150,000 femoral neck fractures occur every year in the USA, and this number will double by 2050 [1-3]. In the Garden classification, Garden I and II fractures describe undisplaced FNFs in older patients [4-6]. The treatment options are conservative (bed rest with or without traction) and surgical (internal fixation) [7]. Surgical treatment was reported to be optimal [8].

\footnotetext{
* Correspondence: emilcai@163.com

'Department of Orthopaedic Surgery, The Second Affiliated Hospital, School of Medicine, Zhejiang University, Jie-fang Road 88, Hangzhou 310009, People's Republic of China

Full list of author information is available at the end of the article
}

However, any surgery is associated with some risk. Patients undergoing conservative treatment enjoyed good outcomes in some studies [9].

Taha et al. found that conservative therapy afforded an undisplaced FNF union rate of only 44.3\% [10]. Ma et al. and Buord et al. reported that the secondary displacement rates during conservative therapy were 41 and 33\%, respectively [11, 12]. However, Raaymakers et al. found that conservative treatment was successful in $85.9 \%$ of patients [9]. Surgery also seemed to be a good option, reducing secondary displacement and the non-union rate. Phillips et al. found that the union rate after surgery was $94.4 \%$ [13]. Chen et al. reported a union rate of $94.6 \%$ [14]. However, up to $22.5 \%$ of patients experienced 
avascular femoral head necrosis after surgery, and a fixation failure problem was also apparent [13].

Several retrospective studies have compared surgery and conservative therapy to treat undisplaced FNF. The three studies of Bentley et al., Manninger et al., and Cserhati et al. recommended surgical treatment of undisplaced FNFs; this was associated with earlier rehabilitation, lower complication rates, and higher functional scores [15-17]. However, of a total of 54 undisplaced FNF patients, Helbig et al. found that 24 (44\%) developed no complications at all during conservative treatment whereas 28 (52\%) required surgery because of early fracture dislocation [18]. No difference between conservative and operative treatment was evident in terms of survival rate, outcome score, or patient satisfaction.

The purpose of this systematic review was to assess all available clinical data on outcomes after surgery and conservative therapy to treat undisplaced FNFs; we mainly focused on the rates of bone union, secondary displacement, and avascular necrosis (AVN).

\section{Methods}

\section{Literature search}

The following sources of data were searched up to 1 October 2016 by three reviewers (DFX, CHZ, CHM): EMBASE, PubMed, OVID, Cochrane Library, Web of Science, Scopus, using the search strategy of (( femoral neck fracture [MeSH Terms]) OR (femoral neck fracture [Title/Abstract])) AND ("Garden I" OR "Garden II" OR "undisplaced" OR "non-displaced")) with no limitation on the year or language of publication. Bibliographies of all the retrieved articles were hand-searched. In addition, we searched Clinical Trial Registry, Current Controlled Trials, Trials Central, Centre Watch, Google Scholar, multiple Websites of orthopedic associations, and conference proceedings for gray literatures. In the papers, we reviewed the references for any other papers we may not have found.

\section{Selection criteria}

The inclusion criteria for the studies were (1) patients with an undisplaced (Garden type I or Garden type II) femoral neck fracture; (2) primarily conservative treatment; (3) primarily surgical treatment; (4) the outcomes reported at least one of the following assessments: time to union, time to weight bearing, secondary displacement, non-union, AVN, and other complications; and (5) RCTs, non-randomized or quasi-randomized controlled trials, prospective cohort trials, or retrospective comparative studies.

The exclusion criteria were (1) displaced femoral neck fracture; (2) case report, reviews, biomechanical, animal study; (3) patients and fracture that had previously been reported; (4) follow-up <6 months; and (5) sample size of $<10$.

\section{Data abstraction and analysis}

Three reviews (DFX, FGB, CYM) extracted relevant data and checked the accuracy independently. Specially, study design and level of evidence, patient demographics (sample size, age, gender), mean follow-up time, loss to followup rate, intervention (technique and treatment protocol), and outcome measurements were all abstracted. The authors of the included trials were written to identify duplicate publication and uncertain data if necessary.

The weighted kappa for the agreement on the study quality between the investigators was 0.85 (95\% confidence interval (CI), 0.77-0.93).

\section{Assessment of trial quality}

Two reviewers (DFX and ZFW) independently assessed the methodological quality of each trial with the modified Critical Appraisal Skills Programme (CASP) [19]. Each trial was scored with 12 questions, for which the score was 1 for "Yes" and 0 for "No" or "Can't tell". Disagreement was evaluated by means of kappa $(\kappa)$ test and resolved by discussion.

\section{Statistical analysis}

All the results were combined and present as the mean value. The rates of union, secondary displacement and non-union, avascular necrosis, bed rest-related complications, 1 year mortality and reoperation could be combined for statistical analysis. Chi-square test and Fisher's exact test were used to detect the difference of the latter two indices between the two treatment groups. The cutoff value of statistically significant difference was adjusted as $\alpha^{\prime}=\alpha /[(k / 2)+1]=0.05 /[(4 / 2)+1]=0.017$, where $k$ was the number of groups. The pooling of the functional assessment data sets was not attempted because of the significant variability in the criteria. Statistical analyses were performed through STATA 12.0 (Stata Corp., College Station, TX, USA).

\section{Results}

\section{Study identification}

The initial literature search yielded 1024 articles including 466 duplicates, after the removal of which 558 articles remained. Of these, 429 were excluded because they did not fulfill our selection or exclusion criteria based on evaluation of the titles and abstracts. The full texts of the remaining 129 papers were reviewed, and 31 [9-15, 17, 20-28] (Fig. 1) were finally included; these dealt with patients with undisplaced FNFs who were managed either non-operatively or operatively. After careful inspection, we found that $>50 \%$ of the patients were lost to follow-up in the study of Manninger et al. [16] 


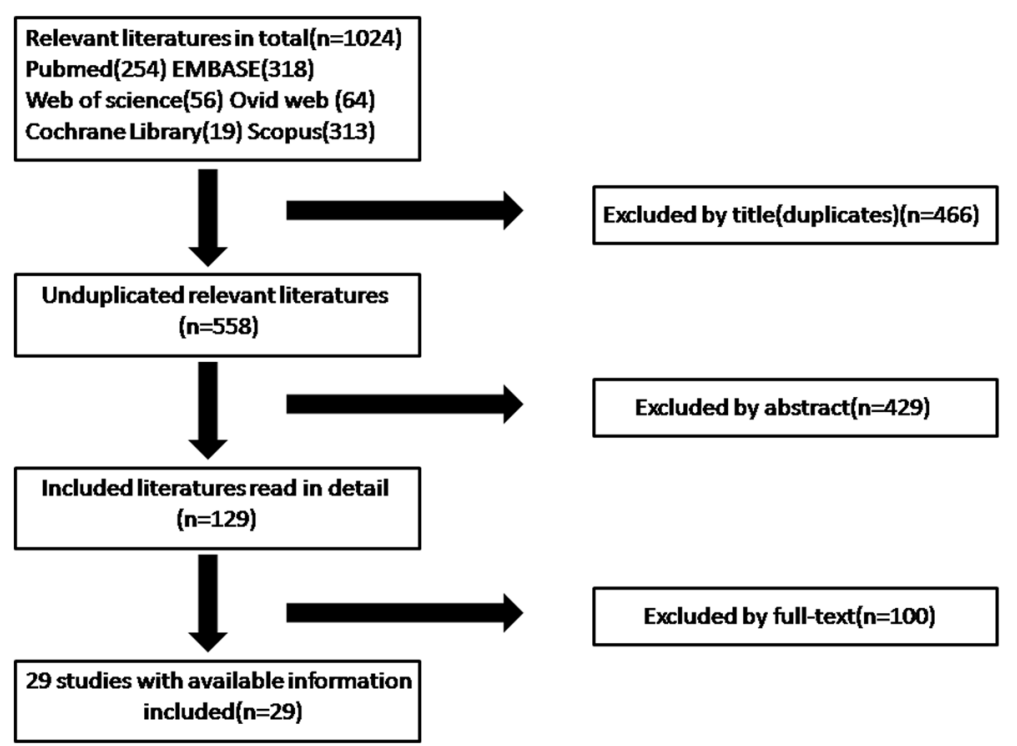

Fig. 1 A PRISMA flowchart illustrated the selection of studies included in our systematic review

Additionally, in another study, patients in the surgical group had initially received conservative therapy [18]. We excluded both studies; 29 studies thus remained.

\section{Patient characteristics and interventions}

Table 1 shows the patient characteristics and the interventions used in all trials. There were 5 prospective cohort studies $[9,12,23,27,29]$ and 24 retrospective cohort studies [10-15, 17, 20-22, 24-26, 28, 30-40]. Of the 29 studies, $2[15,17]$ compared both therapies, 7 [912, 26-28] explored the outcomes of conservative treatment, and 20 [13, 14, 20-25, 29-40] the outcomes of surgery. The surgical options included the use of cancellous screws, single Watson-Jones nails, placement of three Knowles pins, use of a dynamic hip screw, and Smith-Petersen nails. All trials recruited $>10$ patients. In total, 5071 cases were included, of which 1120 were conservatively and 3951 surgically treated. The vast majority of patients were female (female $/$ male $=3211 / 1280$ ). Four papers did not indicate the gender distributions [27, 32, $35,39]$. The mean follow-up duration was $>28.3$ months. The frequency-weighted mean age was $75.0 \pm 4.8$ years for the conservatively treated group and $76.5 \pm 4.1$ years for the surgically treated group.

\section{Outcomes}

Tables 2 and 3 show the outcome measurements of all trials. All trials reported secondary displacement and/or non-union rates, and those of later AVN. Fourteen studies $[9-11,13-15,20,25-28,33,34,40]$ reported union rates. These were $68.8 \%(642 / 933)$ in those receiving conservative treatment and $92.6 \%(635 / 686)$ in those receiving surgical treatment. The secondary displacement rate was $30.0 \%(334 / 1112)$ in conservatively treated patients compared to $0.57 \%(12 / 2124)$ in surgically treated patients. The AVN rate was 10.3\% (39/380) in conservatively treated patients compared with 7.7\% (159/2074) in surgically treated patients. The re-operation rate was $22.6 \%(157 / 696)$ in conservatively treated patients compared with $10.6 \%(336 / 3155)$ in surgically treated patients. Bed rest-related complications developed in $11.4 \%$ (27/237) of conservatively treated patients compared with $4.9 \%(106 / 2149)$ of surgically treated ones. The 1year mortality was $14.7 \%(125 / 852)$ in conservatively treated patients compared with $18 \%(598 / 3318)$ in surgically treated ones.

\section{Literature quality and the risk of bias}

Most studies scored moderately in terms of methodological quality. The overall score was $7.38 \pm 1.37$, rendering the outcomes susceptible to the risk of bias (Table 4). The weighted kappa for agreement on trial quality between reviewers was 0.83 [95\% CI (0.72-0.92)]. The biases included:

1. Selection bias: The fact that few trials were typical RCTs may cause major selection bias. Inconsistencies in evaluation of the type of undisplaced FNF and patient age may constitute other sources of bias.

2. Performance bias: This is attributable to the lack of rehabilitation programs. No consistent method was used for early weight-bearing facilitating recovery.

3. Attrition bias: A small number of trials exhibited considerable loss to follow-up. Most studies reported outcomes incompletely. 
Table 1 Study characteristics and intervention of the trials with operation or non-operation or comparison

\begin{tabular}{|c|c|c|c|c|c|c|c|}
\hline Study & Level & Patients/cases & $\begin{array}{l}\text { Mean age } \\
\text { (years) }\end{array}$ & $\mathrm{F} / \mathrm{M}$ & $\begin{array}{l}\text { Follow-up } \\
\text { (months) }\end{array}$ & $\begin{array}{l}\text { Garden I/ } \\
\text { Garden II }\end{array}$ & Treatment \\
\hline \multicolumn{8}{|l|}{ Comparison studies } \\
\hline \multirow[t]{2}{*}{ Bentley [1] } & IV & $43 / 43$ & 72 & $58 / 8$ & $>36$ & NR & Conservation \\
\hline & & $23 / 23$ & & & $>36$ & NR & $\begin{array}{l}20 \text { Smith-Petersen nailing, } 2 \text { three Moore pins, } \\
1 \text { Charnley compression screw }\end{array}$ \\
\hline \multirow[t]{2}{*}{ Cserhati [2] } & IV & $122 / 122$ & 74.6 & $98 / 24$ & NR & $106 / 16$ & Conservation \\
\hline & & $125 / 125$ & 73.3 & $104 / 21$ & NR & $98 / 27$ & $\begin{array}{l}19 \text { two Smith-Petersen nail, } 5 \text { three cannulated } \\
\text { screws, } 95 \text { three screws + key-hole plage, } \\
6 \text { others }\end{array}$ \\
\hline \multicolumn{8}{|c|}{ Conservative treatment studies } \\
\hline Ma [3] & IV & $115 / 115$ & 71 & $88 / 27$ & NR & $115 / 0$ & \\
\hline Jensen [4] & IV & $128 / 128$ & 73 & $101 / 27$ & 22 & $85 / 43$ & \\
\hline Buorda [5] & III & $57 / 57$ & 81.8 & $50 / 7$ & 20 & NR & \\
\hline Taha [6] & IV & $61 / 61$ & 83 & $48 / 13$ & NR & NR & \\
\hline Raaymakers [7] & III & $170 / 170$ & 69.8 & $130 / 40$ & NR & $167 / 0$ & \\
\hline Raaymakers [8] & III & $319 / 319$ & 72 & NR & NR & $311 / 0$ & \\
\hline Verheyen [9] & IV & $105 / 105$ & 78 & $83 / 22$ & NR & $105 / 0$ & \\
\hline \multicolumn{8}{|c|}{ Operative treatment studies } \\
\hline Rogmark [10] & IV & $224 / 224$ & 81 & $156 / 68$ & 32 & NR & Two Hansson hook pins \\
\hline Lapidus [11] & III & $382 / 382$ & 80.7 & $282 / 100$ & 79.2 & NR & Olmed screws \\
\hline Han [12] & IV & $52 / 52$ & 77.6 & $38 / 14$ & 11.7 & $13 / 39$ & Multiple screws, pins, or dynamic hip screw \\
\hline Phillips [13] & IV & $100 / 100$ & 76.9 & $86 / 14$ & 22.6 & NR & Watson-Jones nail fixation \\
\hline Manohara [14] & IV & $100 / 100$ & 78 & $77 / 23$ & 39 & $85 / 15$ & Screws \\
\hline Kim [15] & IV & $60 / 60$ & 77.5 & $40 / 18$ & 46.8 & $28 / 30$ & Three cannulated screws \\
\hline Chiu [16] & IV & $298 / 305$ & 66 & 197/101 & 75 & NR & Knowles pins \\
\hline Chen [17] & IV & $37 / 37$ & 83.7 & $22 / 15$ & $>24$ & $21 / 16$ & Cancellous screws \\
\hline \multirow[t]{2}{*}{ Makki [18] } & IV & $31 / 31$ & 75 & $22 / 9$ & $>12$ & $2 / 26$ & Dynamic hip screw \\
\hline & & $34 / 34$ & 70 & $20 / 14$ & $>12$ & $9 / 25$ & Dynamic hip screw with anti-rotation screw \\
\hline \multirow[t]{2}{*}{ Parker [19] } & IV & $346 / 346$ & 80.8 & $295 / 51$ & $>12$ & NR & Screw \\
\hline & & $346 / 346$ & 80.8 & $295 / 51$ & $>12$ & NR & Hemiarthroplasty \\
\hline Stromqvist [20] & IV & $85 / 85$ & 78 & NR & $>12$ & NR & Hook Pin \\
\hline Parker [21] & IV & $565 / 565$ & 76 & $435 / 130$ & $>12$ & NR & $\begin{array}{l}\text { A sliding hip } \\
\text { screw or three cannulated screws }\end{array}$ \\
\hline Parker [22] & IV & $112 / 112$ & 76 & NR & 24 & NR & Internal fixation \\
\hline \multirow[t]{3}{*}{ Lee [23] } & IV & $28 / 28$ & 70.1 & $18 / 15$ & $>12$ & NR & Dynamic hip screw \\
\hline & & $22 / 22$ & 74.6 & $13 / 12$ & $>12$ & NR & Dynamic hip screw \\
\hline & & $27 / 27$ & 72.8 & $15 / 17$ & $>12$ & NR & Multiple cannulated screws \\
\hline \multirow[t]{3}{*}{ Hui [24] } & IV & $15 / 15$ & $>80$ & NR & $>6$ & NR & Over 80 years internal fixation \\
\hline & & $16 / 16$ & 72 & NR & $>6$ & NR & 65-79 years internal fixation \\
\hline & & $23 / 23$ & $>80$ & NR & $>6$ & NR & Over 80 years hemiarthroplasty \\
\hline Bjorgul [25] & IV & $225 / 225$ & 80 & $161 / 64$ & 47 & NR & Two cannulated screws \\
\hline \multirow[t]{2}{*}{ Watson [26] } & III & $31 / 31$ & 77.9 & $25 / 6$ & $>24$ & NR & Dynamic hip screw \\
\hline & & $29 / 29$ & 76.7 & $24 / 5$ & $>24$ & NR & Three partially threaded screws \\
\hline \multirow[t]{2}{*}{ Yih [27] } & IV & $46 / 46$ & 72.8 & $24 / 16$ & 33.5 & NR & Dynamic hip screws \\
\hline & & $48 / 48$ & 70.6 & $25 / 19$ & 35.6 & NR & Multiple cannulated screws \\
\hline
\end{tabular}


Table 1 Study characteristics and intervention of the trials with operation or non-operation or comparison (Continued)

\begin{tabular}{|c|c|c|c|c|c|c|c|}
\hline Conn [28] & IV & $375 / 375$ & 77.1 & $75 / 296$ & $>12$ & $N R$ & Three parallel \\
\hline \multirow[t]{2}{*}{ Sikand [29] } & IV & 29/29 & 79 & $21 / 8$ & $>12$ & $N R$ & Hemiarthroplasty \\
\hline & & $110 / 110$ & 77 & $85 / 25$ & $>12$ & NR & Internal fixation \\
\hline
\end{tabular}

$N R$ not recorded

4. Detection bias: This may possibly be caused by nonstandardized or undescribed follow-up schedules.

5. Reporting bias: This is an intrinsic weakness of retrospective cohort studies.

In detail, we restricted the type of FNF to undisplaced fractures. Most studies contained patients with both undisplaced and displaced fractures. It was difficult to isolate data on undisplaced FNF; we therefore established strict selection and exclusion criteria to reduce selection bias as much as possible. Furthermore, differences in surgical methods increased performance bias. Inconsistencies in follow-up and loss to follow-up also increased bias. Most studies were retrospective in nature, rendering reporting bias unavoidable.

\section{Pooled analysis}

As the measurements of patient characteristics and outcomes were consistent among the trials, we pooled these to derive mean values. Overall, surgically treated patients had a shorter time to weight-bearing and a shorter hospital stay. In addition, such patients had a higher union rate, lower rates of secondary displacement and non-union, and a lower rate of bed rest-related complications.

Significant differences were evident between the surgical and the conservative treatment groups in terms of the union rate $(p<0.001)$, the rates of secondary displacement and non-union $(p<0.001)$, and the rate of bed rest-related complications $(p<0.001)$. A trend toward a difference in the AVN rate was also apparent $(p=0.09)$.

\section{Discussion}

To the best of our knowledge, this is the first systematic review to focus on the optimal treatment for undisplaced FNFs. We investigated whether conservative treatment was optimal for the common problem of undisplaced FNFs in the elderly. We developed explicit inclusion and exclusion criteria, assessed the methodological quality of all studies, explored the reproducibility of all selection and assessment criteria, performed quantitative analysis, and explored possible reasons for observed differences among studies. We found data paradox and confirmed the correct data of the original paper [20]. The validity of our findings is strengthened by the fact that we strictly followed the suggestions of the Cochrane
Handbook for Systematic Reviews of Interventions (version 5.0.2) and the PRISMA 2009 checklist.

One of our most important findings is that fractures that were surgically treated had higher union rates and comparable non-union rates to those treated conservatively. Obviously, fixation affords stability and stiffness, directly enhancing the strength of the femoral neck [41, 42]. Biomechanical studies have confirmed that fracture fixation and immobilization affect the pattern of skeletogenic stem cell differentiation into osteoblasts; mechanical fixation would obviously influence neovascularization [43]. Thus, fixation promotes bone union. In some studies $[13-15,20]$, the union rates reached $90 \%$. Fixation failure is a rare complication after surgery to treat undisplaced fractures. The fixation failure rate in our meta-analysis was only $3.3 \%(45 / 1366)$.

Conservative treatment is an option for undisplaced FNFs, the advantage being that surgery is avoided, but most studies revealed a significant risk of displacement during non-operative treatment. The risk varied from 14.1 to $55.7 \%$ [9-12, 26-28]. Verheyen et al. [28] explored the rate of secondary displacement in 105 patients. Forty-eight patients (46\%) were at risk of such displacement; the patient group had a high mean age. Secondary displacement was more common in patients aged $>70$ years, in agreement with the data of Raaymakers [27], who reported secondary instability in $41 \%$ of patients $>70$ years of age. In healthy patients $<70$ years of age, the value was $7 \%$. Secondary displacement is very rare after surgical treatment.

AVN is a well-recognized complication of FNFs, caused by alterations in the blood supply [7, 44]. AVN often develops 2-3 years after treatment. We found no significant difference between the two treatment groups in terms of AVN. However, AVN tended to be less common in surgical patients. Massive rupture of the retinacular vessels may occur when the femoral head is rotated during surgery; this may trigger AVN [45]. Thus, fixation potentially adversely affects the vascularity of the femoral head [46]. On the other hand, fixation prevents micromotion of the fracture site, facilitating vascularity. In Brodetti et al.'s cadaver experimental study [47], they inserted nails or screws into various sites to observe changes in blood supply; they found that such insertions were unlikely to contribute to further devascularization of the femoral head. Bentley et al. [15] followed up patients for $>3$ years and found that, 


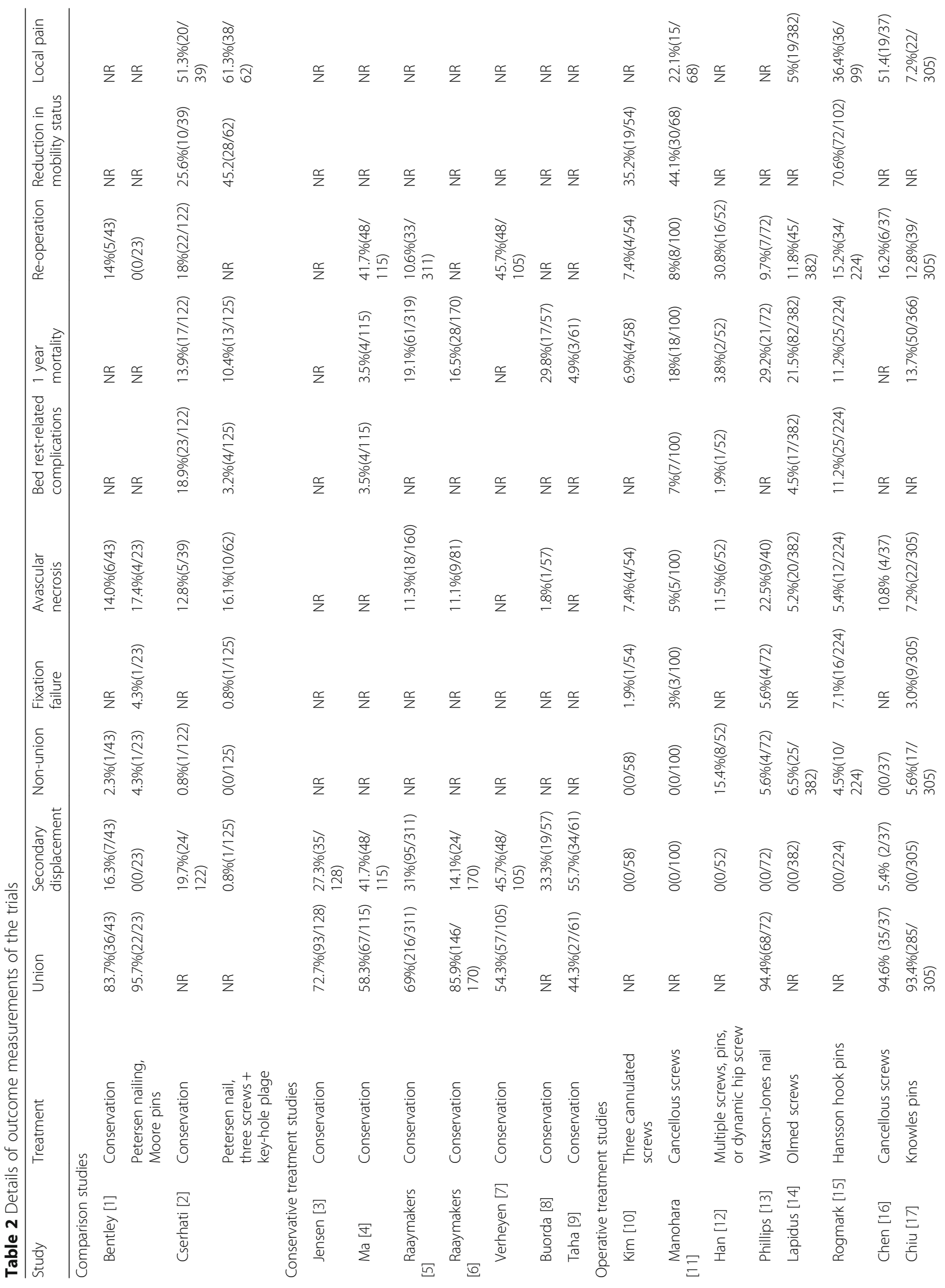




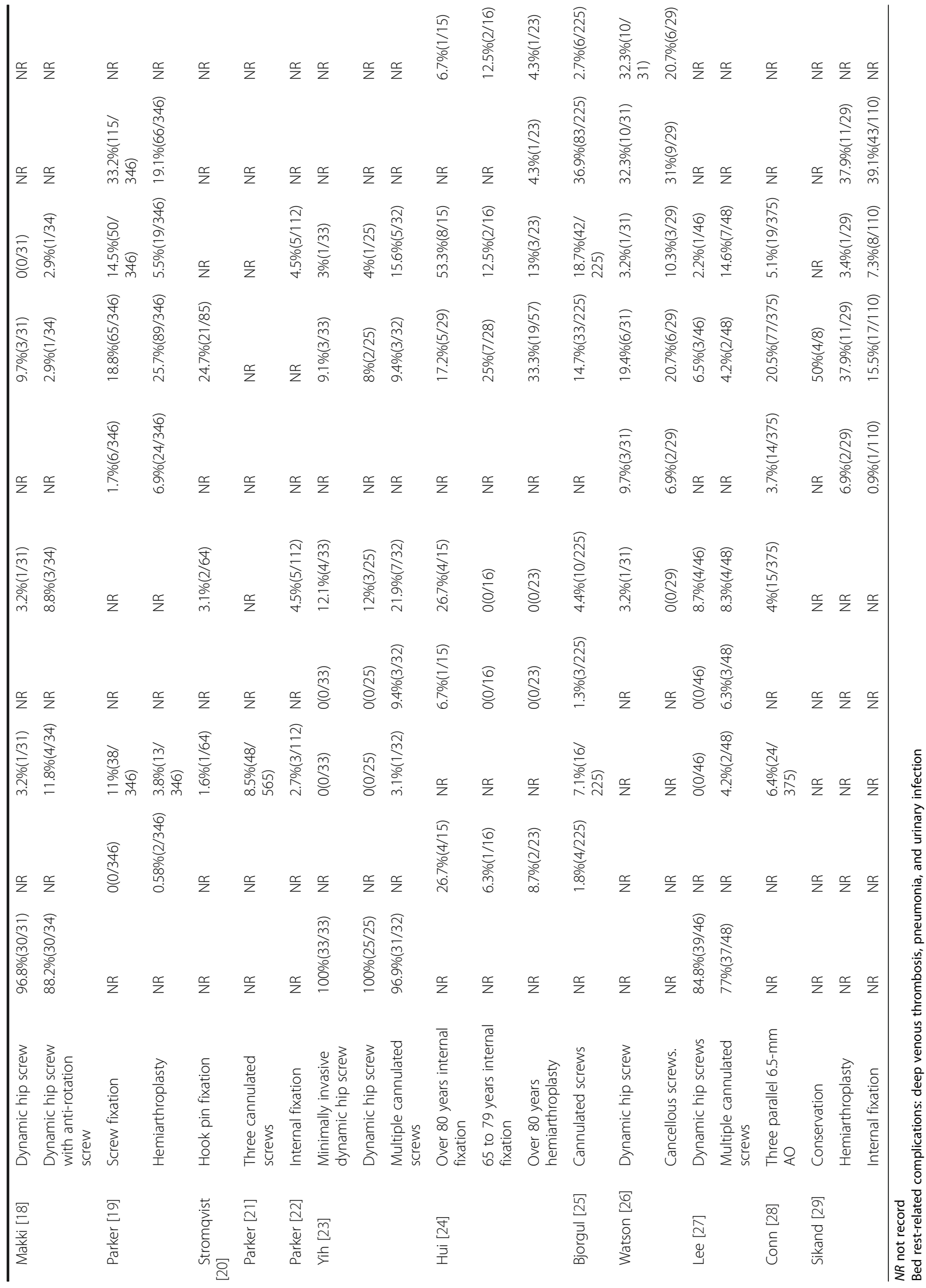


Table 3 Demographics according to treatment group

\begin{tabular}{llll}
\hline Variable & $\begin{array}{l}\text { Conservative } \\
\text { treatment }\end{array}$ & $\begin{array}{l}\text { Surgical } \\
\text { treatment }\end{array}$ & $\begin{array}{l}P \\
\text { value }\end{array}$ \\
\hline Cases & 1120 & 3951 & \\
Mean age (years) & $75.0 \pm 4.8$ & $76.5 \pm 4.1$ & \\
Female/Male & $598 / 160$ & $2555 / 1112$ & \\
Union & $68.8 \%(642 / 933)$ & $92.6 \%(635 / 686)$ & $<0.001$ \\
$\begin{array}{l}\text { Secondary displacement } \\
\text { and non-union }\end{array}$ & $30 \%(334 / 1112)$ & $0.57 \%(12 / 2124)$ & $<0.001$ \\
Avascular necrosis & $10.3 \%(39 / 380)$ & $7.7 \%(159 / 2074)$ & 0.09 \\
$\begin{array}{l}\text { Bed rest-related } \\
\text { complications }\end{array}$ & $11.4 \%(27 / 237)$ & $4.9 \%(106 / 2149)$ & $<0.001$ \\
$\begin{array}{l}1 \text { year mortality } \\
\text { Reoperation }\end{array}$ & $14.7 \%(125 / 852)$ & $18 \%(598 / 3318)$ & 0.02 \\
\hline
\end{tabular}

although no AVN occurred in the first year, AVN did develop after 2 years in both groups. The incidence did not vary greatly between those who underwent conservative (14\%) and surgical (18\%) treatment. Hence, follow-up is very important to $\mathrm{AVN}$ detection.

Re-operation to deal with complications is a commonly reported outcome measure. After conservative treatment, re-operations were principally attributable to secondary displacement and latent AVN $[11,28]$. Nonunion, fixation failure, and $\mathrm{AVN}$ were the most common reasons for re-operation after surgical treatment [7]. The re-operation rate differed significantly $(p<0.01)$ between the two treatment options. Overall, the outcomes were better after surgery. It is true that patients are exposed to extra risks (including anesthesia and bleeding) during surgery. We found no evidence suggesting that complications associated with anesthesia and surgery outweighed the increased risk of fracture-healing complications characteristic of conservative treatment. On the contrary, surgical treatment significantly reduced the risk of fracture displacement and significantly increased the union rate. Patients undergoing re-operation generally underwent hemiarthroplasty or arthroplasty [7, 11]. Overall, surgical treatment must be recommended.

Many clinical reports on treatment outcomes have focused on surgical rather than functional outcome measures. The objective functional results of various treatments are rarely assessed. The Harris hip score (HHS) is the most common modality used to assess hip function. In one study [40] on patients aged $>60$ years, Yih et al. reported an HHS of $84.2 \pm 5.2$ for those treated via insertion of dynamic hip screws and $82.6 \pm 5.1$ for those undergoing osteosynthesis using cannulated screws. Some studies employed fairly crude outcome measures (pain and mobility level documented in a rudimentary manner). In a recent study of 224 patients who completed self-evaluation questionnaires $>3$ years after internal fixation, Rogmark et al. found that $40 \%$ reported average to severe pain when walking and $25 \%$ pain at rest. [25] Functional results are rarely assessed in those treated conservatively. In one comparative study [17], Cserhati et al. recorded the levels of pain and mobility. Of 39 patients, 5.6\% (10/39) reported poorer mobility status after conservative treatment compared with $45.2 \%$ $(28 / 62)$ of those who underwent surgery; $51.3 \%(20 / 39)$ of patients reported severe or moderate pain when weight-bearing after conservative treatment compared with $61.3 \%(38 / 62)$ of those who underwent surgical treatment. It thus seems that conservative treatment afforded better outcomes. In terms of mortality, this was higher $(68 \% ; 83 / 122)$ after conservative treatment than the $50.4 \%(63 / 125)$ after surgical treatment. Therefore, the overall outcome is better after surgical treatment.

In terms of surgery, primary hemiarthroplasty of an undisplaced FNF is a possible alternative treatment. Parker et al. [37] randomized 692 patients with undisplaced FNFs to hemiarthroplasty (346 patients) or internal fixation (346 patients). Fixation was associated with a significantly reduced operative time (43 vs. $67 \mathrm{~min}$ ), less blood loss, and a lower 1-year mortality rate (19 vs. $26 \%)$. The additional benefits of fixation were less pain at 1 year, less reduction in mobility, and a reduced dependence on walking aids. Re-operations were required by $5.5 \%(19 / 346)$ of the hemiarthroplasty group and $14.5 \%(50 / 346)$ of the fixation group. Hui et al. [32] and Sikand et al. [38] also evaluated re-operation and mortality levels. Internal fixation was associated with lower mortality but a greater need for re-operation, compared with hemiarthroplasty. The increased risk of mortality associated with hemiarthroplasty indicates that hemiarthroplasty cannot be recommended to treat an undisplaced FNF.

A precise diagnosis is important prior to choosing a treatment option. Radiography has certain limitations when used to distinguish FNF types, which can result in misdiagnosis. A patient may in fact have a displaced FNF but be diagnosed with an undisplaced one $[6,10]$. In addition, diagnoses using the Garden classification are very inconsistent. Zlowodzki et al. [48] surveyed the preferences of orthopedic surgeons in terms of FNF classification systems and asked whether they thought they could distinguish the four different Garden fracture types. Of all surgeons, 96\% felt that they could distinguish between undisplaced (Garden I/II) and displaced (Garden III/IV) fractures. However, the Garden classification system exhibits great variability. Therefore, X-rays combined with a CT scan should be routinely used for diagnosis [6].

We reviewed the conservative treatments employed [9-12, 15, 17, 26-28]. Careful nursing and optimal physician management allowed gradual mobilization to 


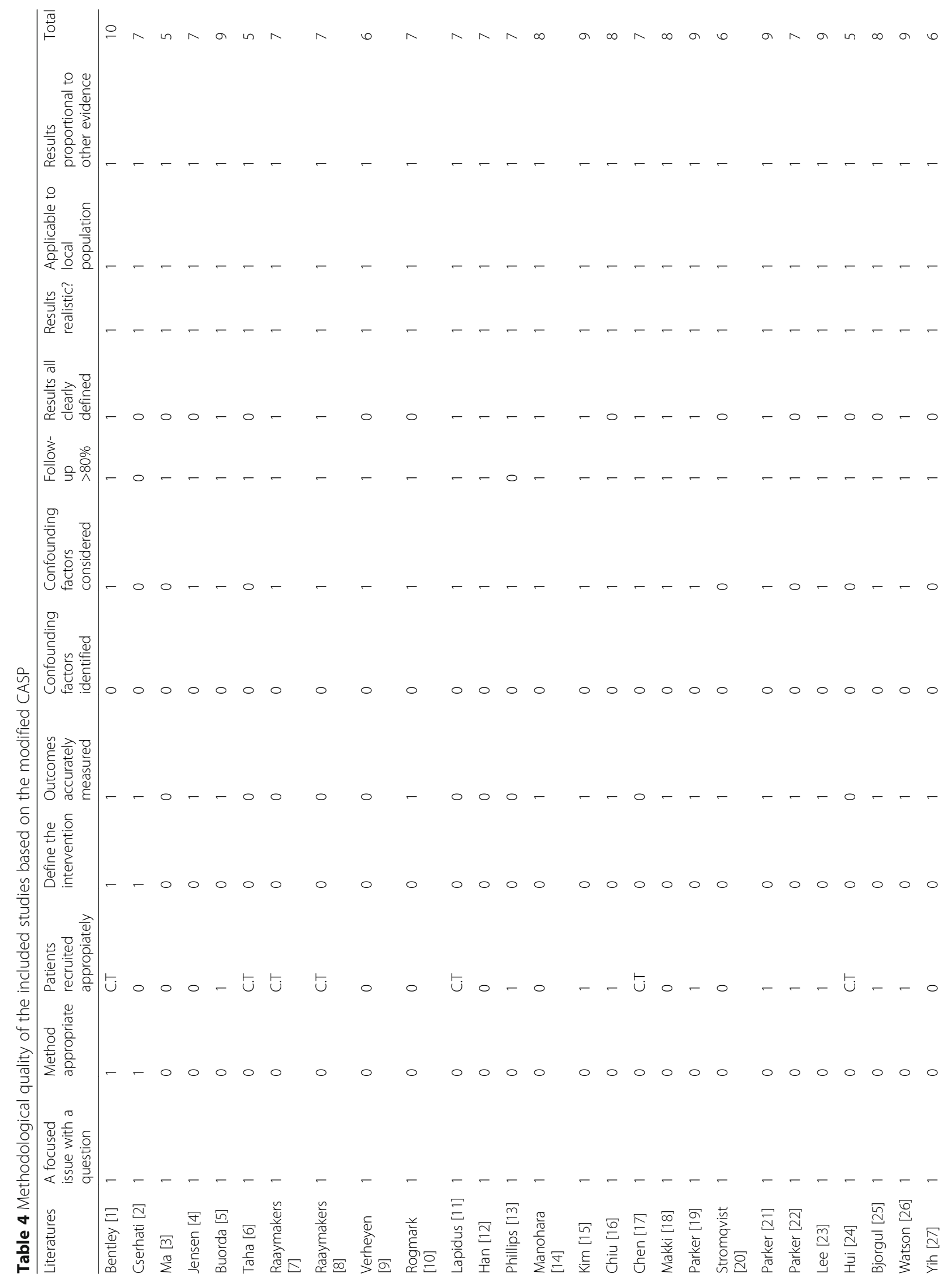




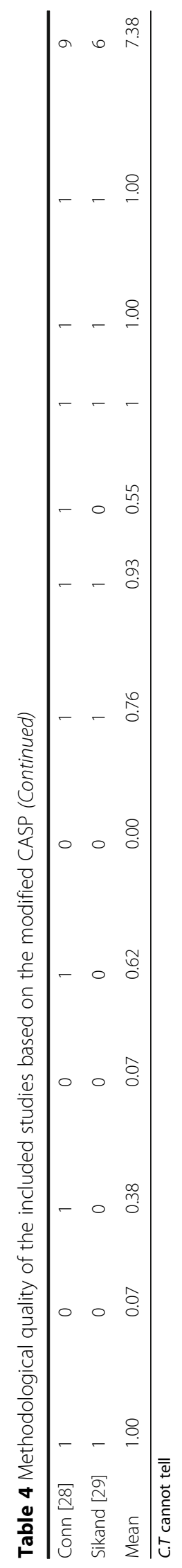


commence with exercises in bed, followed by partial weight-bearing, with the aid of crutches, for $\geq 8$ weeks after fracture. The outcomes were satisfactory $[9,15]$. However, only a few patients adhered to their rehabilitative protocols in the long term. If a patient without a comorbid condition can guarantee good compliance, conservative treatment may also be recommended. In addition, patients with surgical risks must be treated conservatively.

Our work had certain limitations: (1) Most studies were retrospective in nature. Ignoring such studies would have underpowered our analyses and negatively affected the accuracy of our findings. A future strictly designed and adequately powered RCT is essential. (2) We pooled Garden I and Garden II FNFs; their prognoses did not differ greatly. A future study could compare treatment outcomes between patients with these two types of FNF. (3) We explored possible publication bias using Begg, Egger, and funnel plots. The included studies did not meet the standards required by these methods; it was thus difficult to evaluate publication bias.

Ideally, a randomized trial would reveal whether surgical or conservative treatment should be preferred for undisplaced FNFs. We suggest that future studies should prospectively compare the outcomes and complication rates of different internal fixation techniques and conservative methods.

\section{Conclusions}

Surgery to treat undisplaced FNFs was associated with a higher union rate and a tendency toward reduction in the AVN rate. Careful treatment and follow-up are essential. We suggest that $\mathrm{CT}$ should be routinely used to assist in precise diagnosis. Follow-up should be maintained for at least 2 years, allowing AVN detection (if AVN develops) and treatment.

\section{Abbreviations}

AVN: Avascular necrosis; FNF: Femoral neck fractures; HHS: Harris hip score

\section{Acknowledgements}

We thank all the corresponding authors from the included trials for their kind assistance in obtaining additional data that contributed to our systematic review. The project was funded by the National Natural Science Foundation of China $(81371954,81472113)$. All funding sources were independent and had no influence on the study design, the data extraction, analyses, interpretation of the data, writing of this article, or in the decision to submit the article for publication.

\section{Funding}

The study was funded by the National Natural Science Foundation of China (81371954, 81472113).

\section{Availability of data and materials}

All the data of the manuscript are presented in the paper or additional supporting files.

\section{Authors' contributions}

All authors listed have made substantial contributions to the study. XZC conceived and designed the experiments, contributed reagents/materials/ analysis tools. DFX and FGB wrote the manuscript and participated in performing the experiments and analyzing the data. CYM took part in performing the experiments. ZFW participated in the analysis of data. All authors read and approved the final manuscript.

\section{Competing interests}

The authors declare that they have no competing interests.

\section{Consent for publication}

Not applicable.

Ethics approval and consent to participate Not applicable.

\section{Grants}

The corresponding author has the right to grant on behalf of all authors and does grant on behalf of all authors, a worldwide licence to the publishers and its licensees in perpetuity, in all forms, formats and media (whether known now or created in the future), to (i) publish, reproduce, distribute, display, and store the contribution, (ii) translate the contribution into other languages, create adaptations, reprints, include within collections and create summaries, extracts and/or, abstracts of the contribution, (iii) create any other derivative work(s) based on the contribution, (iv) to exploit all subsidiary rights in the contribution, ( $v$ ) the inclusion of electronic links from the contribution to third party material wherever it may be located; and (vi) licence any third party to do any or all of the above.

\section{Author details}

${ }^{1}$ Department of Orthopaedic Surgery, The Second Affiliated Hospital, School of Medicine, Zhejiang University, Jie-fang Road 88, Hangzhou 310009, People's Republic of China. ${ }^{2}$ Department of Orthopaedic Surgery, The First Affiliated Hospital of Zhengzhou University, Zhengzhou 450001, People's Republic of China. ${ }^{3}$ Department of Orthopaedic Surgery, The Fourth Affiliated Hospital, School of Medicine, Zhejiang University, Yiwu 322000, People's Republic of China.

Received: 22 November 2016 Accepted: 3 February 2017

Published online: 10 February 2017

\section{References}

1. Kannus P, Parkkari J, Sievanen H, Heinonen A, Vuori I, Jarvinen M. Epidemiology of hip fractures. Bone. 1996;18(1 Suppl):57s-63s.

2. Gullberg B, Johnell O, Kanis JA. World-wide projections for hip fracture. Osteoporos Int. 1997;7(5):407-13.

3. Cooper C, Campion G, Melton 3rd LJ. Hip fractures in the elderly: a worldwide projection. Osteoporos Int. 1992;2(6):285-9.

4. Thomsen NO, Jensen CM, Skovgaard N, Pedersen MS, Pallesen P, SoeNielsen $\mathrm{NH}$, et al. Observer variation in the radiographic classification of fractures of the neck of the femur using Garden's system. Int Orthop. 1996; 20(5):326-9

5. Lasanianos N, Kanakaris N, Giannoudis PV. An occult acetabular fracture preceding a femoral neck fracture. Orthopedics. 2009;32(8). doi:10.3928/ 01477447-20090624-28.

6. Melvin JS, Mataszewski P, Scolaro J, Baldwin K, Mehta S. The role of computed tomography in the diagnosis and management of femoral neck fractures in the geriatric patient. Orthopedics. 2011;34(2):87. doi:10.3928/ 01477447-20101221-18.

7. Florschutz AV, Langford JR, Haidukewych GJ, Koval KJ. Femoral neck fractures: current management. J Orthop Trauma. 2015;29(3):121-9.

8. Miller BJ, Callaghan JJ, Cram P, Karam M, Marsh JL, Noiseux NO. Changing trends in the treatment of femoral neck fractures: a review of the american board of orthopaedic surgery database. J Bone Joint Surg Am. 2014;96(17): e149. doi:10.2106/jbjs.m.01122.

9. Raaymakers EL, Marti RK. Non-operative treatment of impacted femoral neck fractures. A prospective study of 170 cases. J Bone Joint Surg Br. 1991;73(6):950-4.

10. Taha ME, Audige L, Siegel G, Renner N. Factors predicting secondary displacement after non-operative treatment of undisplaced femoral neck fractures. Arch Orthop Trauma Surg. 2015:135(2):243-9. doi:10.1007/s00402014-2139-9. 
11. Ma S, Wang K, Tong Z, Zhang M, Wang W. Outcome of non-operative management in Garden I femoral neck fractures. Inj Int J Care Inj. 2006; 37(10):974-8. doi:10.1016/j.injury.2006.04.136.

12. Buord JM, Flecher X, Parratte S, Boyer L, Aubaniac JM, Argenson JN. Garden I femoral neck fractures in patients 65 years old and older: is conservative functional treatment a viable option? Orthop Traumatol. 2010;96(3):228-34.

13. Phillips JE, Christie J. Undisplaced fracture of the neck of the femur: results of treatment of 100 patients treated by single Watson-Jones nail fixation. Injury. 1988;19(2):93-6.

14. Chen WC, Yu SW, Tseng IC, Su JY, Tul YK, Chen WJ. Treatment of undisplaced femoral neck fractures in the elderly. J Trauma Inj Infect Crit Care. 2005;58(5):1035-9. doi:10.1097/01.ta.0000169292.83048.17.

15. Bentley G, TREATMENT OF. Non-displaced fractures of the femoral-neck. Clin Orthop Relat Res. 1980;152:93-101.

16. Manninger J, Kazar G, Salacz T, Varga A. Conservative or surgical treatment of undisplaced (impacted) femoral neck fractures? Unfallchirurgie. 1990; 16(3):116-21.

17. Cserhati P, Kazar G, Manninger J, Fekete K, Frenyo S. Non-operative or operative treatment for undisplaced femoral neck fractures: a comparative study of 122 non-operative and 125 operatively treated cases. Injury. 1996; 27(8):583-8.

18. Helbig L, Werner M, Schneider S, Simank HG. Garden I femoral neck fractures: conservative vs operative therapy. Orthopade. 2005;34(10):1040-5.

19. No authors listed. Critical Appraisal Skills Programme UK Website. http:// www.casp-uk.net. Date last accessed 31 May 2013.

20. Chiu FY, Lo WH, Yu CT, Chen TH, Chen CM, Huang CK. Percutaneous pinning in undisplaced subcapital femoral neck fractures. Inj Int J Care Inj. 1996;27(1):53-5. doi:10.1016/0020-1383(95)00157-3.

21. Han SK, Song HS, Kim R, Kang SH. Clinical results of treatment of garden type 1 and 2 femoral neck fractures in patients over 70-year old. Eur J Trauma Emerg Surg. 2015. doi:10.1007/s00068-015-0528-6.

22. Kim JW, Byun S-E, Chang JS. The clinical outcomes of early internal fixation for undisplaced femoral neck fractures and early full weight-bearing in elderly patients. Arch Orthop Trauma Surg. 2014;134(7):941-6. doi:10.1007/ s00402-014-2003-y.

23. Lapidus $\sqcup$, Charalampidis A, Rundgren J, Enocson A. Internal fixation of garden i and II femoral neck fractures: posterior tilt did not influence the reoperation rate in 382 consecutive hips followed for a minimum of 5 years. J Orthop Trauma. 2013;27(7):386-90.

24. Manohara R, Liang S, Huang D, Krishna L. Cancellous screw fixation for undisplaced femoral neck fractures in the elderly. J Orthop Surg (Hong Kong). 2014;22(3):282-6.

25. Rogmark C, Flensburg L, Fredin H. Undisplaced femoral neck fractures-no problems? A consecutive study of 224 patients treated with internal fixation. Injury. 2009;40(3):274-6.

26. Jensen J, Hogh J. Fractures of the femoral neck. A follow-up study after nonoperative treatment of Garden's stage 1 and 2 fractures. Injury. 1983;14(4):339-42.

27. Raaymakers EL. The non-operative treatment of impacted femoral neck fractures. Injury. 2002;33 Suppl 3:C8-14.

28. Verheyen CC, Smulders TC, van Walsum AD. High secondary displacement rate in the conservative treatment of impacted femoral neck fractures in 105 patients. Arch Orthop Trauma Surg. 2005;125(3):166-8. doi:10.1007/ s00402-004-0791-1.

29. Watson A, Zhang Y, Beattie S, Page RS. Prospective randomized controlled trial comparing dynamic hip screw and screw fixation for undisplaced subcapital hip fractures. ANZ J Surg. 2013;83(9):679-83. doi:10.1111/j.1445-2197.2012.06256.x.

30. Bjorgul K, Reikeras O. Outcome of undisplaced and moderately displaced femoral neck fractures. Acta Orthop. 2007;78(4):498-504. doi:10.1080/ 17453670710014149 .

31. Conn KS, Parker MJ. Undisplaced intracapsular hip fractures: results of internal fixation in 375 patients. Clin Orthop Relat Res. 2004;421:249-54.

32. Hui AC, Anderson GH, Choudhry R, Boyle J, Gregg PJ. Internal fixation or hemiarthroplasty for undisplaced fractures of the femoral neck in octogenarians. J Bone Joint Surg Br. 1994;76(6):891-4.

33. Lee YS, Chen SH, Tsuang YH, Huang HL, Lo TY, Huang CR. Internal fixation of undisplaced femoral neck fractures in the elderly: a retrospective comparison of fixation methods. J Trauma. 2008;64(1):155-62. doi:10.1097/ TA.0b013e31802c821c.

34. Makki D, Mohamed AM, Gadiyar R, Patterson M. Addition of an anti-rotation screw to the dynamic hip screw for femoral neck fractures. Orthopedics. 2013;36(7):e865-8. doi:10.3928/01477447-20130624-15.
35. Parker M, Cawley S, Palial V. Internal fixation of intracapsular fractures of the hip using a dynamic locking plate: two-year follow-up of 320 patients. Bone Joint J. 2013;95-b(10):1402-5. doi:10.1302/0301-620x.95b10.31511.

36. Parker MJ, Raghavan R, Gurusamy K. Incidence of fracture-healing complications after femoral neck fractures. Clin Orthop Relat Res. 2007;458: 175-9. doi:10.1097/BLO.0b013e3180325a42.

37. Parker MJ, White A, Boyle A. Fixation versus hemiarthroplasty for undisplaced intracapsular hip fractures. Injury. 2008;39(7):791-5. doi:10.1016/ j.injury.2008.01.011.

38. Sikand M, Wenn R, Moran CG. Mortality following surgery for undisplaced intracapsular hip fractures. Injury. 2004;35(10):1015-9. doi:10.1016/j.injury. 2004.01.004

39. Stromqvist B, Hansson LI, Nilsson LT, Thorngren KG. Hook-pin fixation in femoral neck fractures. A two-year follow-up study of 300 cases. Clin Orthop Relat Res. 1987:(218):58-62.

40. Yih-Shiunn L, Chien-Rae H, Wen-Yun L. Surgical treatment of undisplaced femoral neck fractures in the elderly. Int Orthop. 2007;31(5):677-82. doi:10. 1007/s00264-006-0243-3.

41. Upasani V, Kishan S, Oka R, Mahar A, Rohmiller M, Pring M, et al. Biomechanical analysis of single screw fixation for slipped capital femoral epiphysis: are more threads across the physis necessary for stability? J Pediatr Orthop. 2006:26(4):474-8. doi:10.1097/01.bpo.0000217732.24041.81.

42. Miyanji F, Mahar A, Oka R, Pring M, Wenger D. Biomechanical comparison of fully and partially threaded screws for fixation of slipped capital femoral epiphysis. J Pediatr Orthop. 2008;28(1):49-52. doi:10.1097/bpo. ob013e31815a5fa4.

43. Zhao F, Zhou Z, Yan Y, Yuan Z, Yang G, Yu H, et al. Effect of fixation on neovascularization during bone healing. Med Eng Phys. 2014;36(11):143642. doi:10.1016/j.medengphy.2014.07.002.

44. Gierer P, Mittlmeier T. Femoral neck fracture. Unfallchirurg. 2015;118(3):25970. doi:10.1007/s00113-014-2729-6.

45. Bachiller FG, Caballer AP, Portal LF. Avascular necrosis of the femoral head after femoral neck fracture. Clin Orthop Relat Res. 2002;399:87-109.

46. Linde F, Andersen E, Hvass I, Madsen F, Pallesen R. Avascular femoral head necrosis following fracture fixation. Injury. 1986;17(3):159-63.

47. Brodetti A. The blood supply of the femoral neck and head in relation to the damaging effects of nails and screws. J Bone Joint Surg. 1960;42-B:794-801.

48. Zlowodzki M, Bhandari M, Keel M, Hanson BP, Schemitsch E. Perception of Garden's classification for femoral neck fractures: an international survey of 298 orthopaedic trauma surgeons. Arch Orthop Trauma Surg. 2005;125(7): 503-5. doi:10.1007/s00402-005-0022-4.

\section{Submit your next manuscript to BioMed Central and we will help you at every step:}

- We accept pre-submission inquiries

- Our selector tool helps you to find the most relevant journal

- We provide round the clock customer support

- Convenient online submission

- Thorough peer review

- Inclusion in PubMed and all major indexing services

- Maximum visibility for your research

Submit your manuscript at www.biomedcentral.com/submit 